\title{
UM ESTUDO SOBRE O ENSINO DE MÚSICA NA EDUCAÇÃO BÁSICA PELA VISÃO DA GESTÃO ESCOLAR
}

\author{
A STUDY ABOUT THE TEACHING OF MUSIC IN BASIC \\ EDUCATION BASED ON SCHOOL MANAGEMENT
}

\section{UM ESTUDIO SOBRE LA ENSEÑANZA DE MUSICA EM LA EDUCACIÓN BÁSICA A PARTIR DE LA VISIÓN DE LA GESTIÓN ESCOLAR}

\author{
Maicon Dorigatti ${ }^{1}$ \\ Terciane Ângela Luchese 2
}

\begin{abstract}
RESUMO
Entendendo o papel fundamental que a gestão escolar desempenha para a articulação do ensino de música na Educação Básica, esta pesquisa teve por objetivo analisar os processos de introdução, construção e reverberações do ensino de música na rede privada a partir da visão da gestão, baseando-se na necessidade cultural de sua abordagem e embasada na legislação que a torna obrigatória. A pesquisa foi realizada em cinco escolas particulares da Serra Gaúcha e a escolha se deu por entender que a rede possui, a princípio, melhores condições de proporcionar um ensino de qualidade, principalmente pelos aspectos estruturais. Constatou-se que mesmo no setor privado ela não é garantida em sua totalidade, sendo trabalhada em maioria como atividades laterais ou extracurriculares, não estando presente de forma regular. Na maior parte, existe a construção de um discurso da sua importância, mas de forma genérica, falta a prática concreta do seu ensino.
\end{abstract}

Palavras-chave: Educação Básica. Ensino de música. Gestão.

\begin{abstract}
Understanding the importance of management in the articulation between basic education and the teaching of music, this study aims to analyze the processes of introduction, construction and the reverberation of the teaching of music inside private schools from the perspective of the management, based on the cultural necessity of its approach and on the legislation that makes it compulsory. The research was conducted in five private schools of the Serra Gaúcha. This choice was made because we recognize private schools have better conditions to provide a qualified education, mainly in the face of infrastructure aspects. It was found that, even in the private education, the teaching of music is not guaranteed in its entirety, being mostly worked as a side or extra activity, not being present on a regular basis. There is a talk about the importance of the teaching of music, but still in a generic line. The necessary is the real practice of its teaching.
\end{abstract}

Keywords: Basic Education. Teaching of music. School management.

\section{RESUMEN}

Entendiendo el papel fundamental que la gestión escolar desempeña para la articulación de la enseñanza de música en la Educación Básica, esta

\footnotetext{
${ }^{1}$ Universidade de Caxias do Sul, Mestre em Educação, Professor no Município de Caxias do Sul/RS, Integrante do Grupo de Pesquisa GPFORMA Serra, mdorigatti@ucs.br, ORCID: https://orcid.org/0000-0002-0521-7570, Lattes: http://lattes.cnpq.br/6949150396213231.

${ }^{2}$ Universidade de Caxias do Sul, Doutora em Educação, Professora do Programa de PósGraduação em Educação e Programa de Pós-Graduação em História, Pesquisadora PQ CNPq e Pesquisador Gaúcho FAPERGS. Líder do GRUPHEIM. taluches@ucs.br, ORCID: https://orcid.org/0000-0002-6608-9728, Lattes: http://lattes.cnpq.br/7640634913198342.
} 
investigación tuvo por objetivo analizar los procesos de introducción, construcción y reverberaciones de la enseñanza de música en la red privada a partir de la visión de la gestión, basándose en la necesidad cultural de su abordaje y basada en la legislación que la vuelve obligatoria. La investigación fue realizada en cinco escuelas particulares de la Sierra de Rio Grande do Sul y la elección se dio por entender que la red posee, en principio, mejores condiciones de proporcionar una enseñanza de calidad, principalmente por los aspectos estructurales. Se constató que aun en el sector privado no es garantida en su totalidad, siendo trabajada la mayoría de las veces como actividades laterales o extracurriculares, no estando presente de forma regular. En la mayor parte, existe la construcción de un discurso da su importancia, pero de forma genérica, falta la práctica concreta de su enseñanza.

Palabras clave: Educación Básica. Enseñanza de música. Gestión.

\section{INTRODUÇÃO}

“Os sonhos são projetos pelos quais se luta” (FREIRE, 2014, p. 62).

A epígrafe de abertura do artigo escrita por Freire nos remete ao desejo de projetarmos sonhos para o campo educacional e lutarmos para que se concretizem, aproximando o que sabemos daquilo que fazemos. Neste sentido, objetivamos refletir sobre como gestores da rede privada da educação básica pensam a inserção, o planejamento e a manutenção do ensino de música na escola, o lugar e a importância. Seu ensino está previsto em legislação, mas sabemos que isso não basta. São inúmeras as contribuições ao se trabalhar as linguagens artísticas na escola. Os saberes relacionados a elas contribuem para a formação do sujeito em seus processos criativos, inventivos, humanos e de significação quanto a um pensamento artístico. Sendo espaço de formação e ambiente de aprendizagem, não apenas se espera que a escola desenvolva atividades relacionadas às artes, como é sua incumbência, conforme os dispositivos legais. Dentre estes preceitos, na disciplina de Artes se inserem diferentes linguagens, e entre elas está a música ${ }^{1}$.

O ensino de música nas escolas em algumas atividades é restringido ou mesmo impossibilitado por dificuldades estruturais que envolvem falta de materiais ou espaço adequado, principalmente nas escolas públicas, mas não exclusivamente. Tais constatações nos levaram a pesquisar uma realidade outra, a da rede privada. Os critérios de escolha partiram do pressuposto de que a escola particular, à princípio, poderia ter melhores condições de ofertar ensino adequado de música, principalmente pelo aspecto estrutural, tendo condições de arcar com os custos de disponibilização de sala com espaço adequado, computadores e

\footnotetext{
${ }^{1}$ A Lei 11.769/2008 institui a obrigatoriedade do ensino de música na Educação Básica e mais recentemente a BNCC reiterou esse compromisso. Sobre a temática da obrigatoriedade do ensino de música ver Alvarenga e Mazzotti (2012). Como reconhecem Queiroz e Marinho (2009, p. 62) "é possível afirmar que no Brasil já temos uma trajetória histórica, educativa e cultural que nos permite uma reflexão crítica acerca de perspectivas e caminhos concretos que possam subsidiar a inserção da educação musical nas escolas. Mas, mesmo considerando a trajetória de mais de um século, é evidente que as questões relacionadas à presença da música na escola e o debate em torno da sua inserção real na estrutura curricular da Educação Básica ganharam maior visibilidade a partir da Lei 11.769".
} 
softwares para o trabalho de música e tecnologia ${ }^{2}$, instrumentos musicais para estudo e prática e professor com formação específica em música.

Em tempos de enaltecimento e exigência de conhecimentos de áreas mais exatas pela excessiva cobrança em provas de vestibulares e concursos, para uma maior elucidação da necessidade de ter atividades que envolvam o ensino de música é fundamental que a equipe gestora da instituição prime por esta prática. Sua posição quanto ao componente que compõe o currículo explicita aspectos de investimentos, bem como as contribuições e relevância das aulas na formação integral dos alunos. É importante delimitar o espaço curricular, a estrutura disponibilizada e se existe dificuldades para sua manutenção. Sabemos que "criar, vivenciar, apreciar e interpretar músicas são práticas que devem constituir a base das aulas de música" (QUEIROZ e MARINHO, 2009, p. 65), mas pode ir além, pois

\begin{abstract}
Entendemos que a partir de práticas de criação, interpretação, descoberta e vivência musical, bem como de propostas lúdicas, diversificadas e eficazes de ensino, o educador musical concretizará caminhos relevantes para a sua atuação docente, podendo, dessa forma, propiciar uma formação ampla e plena do indivíduo (QUEIROZ e MARINHO, 2009, p. 73).
\end{abstract}

Partindo das conjecturas que compreendem a complexa relação que envolve a instituição escolar, esta pesquisa parte do questionamento: quais os aspectos tidos como fundamentais para a inserção, o planejamento e a manutenção do ensino de música na escola , a partir da visão da gestão escolar? Assim, o tema deste trabalho se dá a partir desta perspectiva de análise, entendendo que a gestão tem papel fundamental na articulação e constituição de condições de possibilidade. Como objetivos a intenção de identificar se os gestores tem consciência da relevância não somente no cenário educacional, mas de formação integral do sujeito; como ocorre a inserção, o planejamento e a manutenção do ensino de música na escola; se os gestores apontam a legislação educacional em suas condutas; e as possibilidades proporcionadas para o enriquecimento cultural em sua comunidade escolar.

Para obter dados para esta análise, efetuou-se um trabalho de pesquisa envolvendo coordenadores pedagógicos e diretores de cinco escolas, sendo duas de Caxias do Sul e três de Bento Gonçalves, municípios da serra gaúcha. A escolha pela equipe gestora e coordenação pedagógica $^{3}$ se deu por entender que suas funções dão conta de saber quais as especificidades que justificam a inclusão ou exclusão do ensino de música na instituição.

O perfil profissional dos educadores os quais a gestão faz referência é significativo quanto a sua formação e área de atuação dentro das linguagens artísticas. Informações quanto

\footnotetext{
${ }^{2}$ Por música e tecnologia se entende o uso de softwares nos processos de criação/composição, gravação, estudo de percepção, música eletrônica, armazenamento e execução de músicas.

${ }^{3}$ Equipe gestora pensada como o grupo que intermedeia e articula a concepção do ensino com a equipe de docentes, os alunos e suas famílias, e a comunidade como um todo.
} 
a gênero, idade ou tempo de atuação não foram consideradas para esta pesquisa, pois não tinhamos este intuito.

O convite aos participantes decorreu de contatos com profissionais da área e indicação de colegas de atuação. O instrumento de pesquisa realizado foi por meio de questionário online disponibilizado pelo site Google e enviado aos gestores. Essa ferramenta permite a edição das perguntas, assim como facilidade no levantamento de dados obtidos. Ainda possibilita maior alcance de pessoas por não ser necessário estar em contato individual e exclusivo. No entanto, da mesma forma que a ausência de contato pessoal facilita o processo de envio, consideramos que dificulta a obtenção de respostas, já que o público referenciado não tem necessariamente uma preocupação em participar da pesquisa ou um compromisso com o retorno. Também interfere negativamente o fato de utilizar esta ferramenta é algo bastante comum, o que gera certa "poluição virtual". Ainda, o formato de questionário fechado impossibilita uma interação que uma entrevista individual poderia proporcionar, delineando outros caminhos durante o diálogo. Ponderamos isto como pontos a serem considerados na análise dos dados construídos a partir de tal metodologia.

As principais contribuições que embasam teoricamente a urgência e a carência de um olhar dedicado à prática educativa no âmbito educacional, são de autores com obras dedicadas exclusivamente ao tema, apresentando pesquisas e reflexões direcionadas aos aspectos legislativos da educação e didáticos de sala de aula. Dentre eles, podemos destacar Loureiro (2012), Penna (2012) e Souza (2019).

O texto está organizado em três momentos: no primeiro são apresentadas as legislações que respaldam o ensino de música nas escolas de Educação Básica; no segundo são destacadas considerações sobre seus contextos e práticas no ambiente social e educacional; no terceiro são expostas as respostas dos gestores, bem como a análise das mesmas.

\section{ENSINO DE MÚSICA NAS ESCOLAS E AS PRESCRIÇÕES LEGAIS}

"o educador progressista, capaz e sério, não apenas deve ensinar muito bem sua disciplina, mas desafiar o educando a pensar criticamente a realidade social, política e histórica em que é uma presença" (FREIRE, 2014, p. 49).

O ensino de música no Brasil passou por diferentes momentos entre valorização e desvalorização no currículo da Educação Básica. Foi marcado por momentos de enaltecimento, como no governo Getúlio Vargas que o usou como umas de suas ferramentas do Nacionalismo, quando a música nas escolas serviu na área de ensino e educação cívica, sendo o ensino musical voltado ao público jovem das escolas e dispondo da prática de canto em grandes coros/grupos como principal ferramenta musical (TINHORÃO, 1998). Foi 
diminuída quando em 1971, no auge da ditadura militar, foi promulgado decreto que a extinguiu dos currículos escolares de $1^{\circ}$ e $2^{\circ}$ graus, a mantendo apenas dentro da disciplina de Educação Artística, a qual seria responsável por abranger artes plásticas, teatro e música LDB $n^{\circ}$. 5.692/71-, num contexto em que o professor tem uma atuação polivalente, o que demonstra a despreocupação relegada às disciplinas artísticas (LOUREIRO, 2012). Mais recentemente, tem sido demarcada por práticas direcionadas ao ensino de artes visuais, a partir da ausência formativa por parte de professores na área da música. Desse modo, “a história da educação musical escolar no Brasil tem atravessado por diferentes momentos e processos que foram definindo as diversas formas e modalidades de inclusão da música nas escolas" (LOPARDO, 2014, p. 19). Ainda conforme Lopardo (2014, p. 21):

Claramente identificadas nas últimas décadas, a forte tendência de integrar as áreas artísticas de conhecimento na oferta educativa, fez com que a música estivesse garantida ou por uma opção da direção escolar ou pela presença de um professor qualificado nas diferentes artes que pudesse interagir livremente com as quatro linguagens: teatro, música, artes visuais e dança.

Assim, a disciplina de Artes trabalha com uma visão integrada das linguagens, permitindo e ao mesmo tempo reivindicando diferentes formações e uma visão mais integradora por parte do professor atuante, o que não deve impor, no entanto, uma atuação polivalente.

Faz-se necessário além de um engajamento para o ensino musical nas escolas, estar em consonância com os aspectos legais que a efetivam e legitimam como obrigatoriedade curricular. Em análise, o Estado, onde se encontra o poder da classe dirigente, tem a seu cargo a formulação da legislação educacional e outros termos normativos, sua imposição e fiscalização. A sociedade civil, composta também por associações privadas, entre elas a escola, é o campo onde se situa o sistema educacional, contando com corpo efetivo de gestores escolares, professores e alunos, além de seus correlacionados (funcionários diversos, familiares), sendo nela que as leis são implantadas e efetivadas (PENNA, 2012).

Em 20 de dezembro de 1996, deu-se a sanção da Lei nº 9.394/96 em substituição à lei vigente de 1971. Nesta nova diretriz, na agora disciplina de Artes, ficaram especificados seus objetivos educacionais, sua projeção social e o perfil profissional por parte do docente (BRASIL, 1996). Nela já consta a inserção da música no currículo escolar. Na LDB 9.394/96 estabelece que o ensino de arte deve ser obrigatório em toda a educação básica (artigo 26, $\left.\S 2^{\circ}\right)$.

No início do século XXI, diversos componentes da sociedade uniram-se na tentativa de mudar o quadro educativo, dando origem ao Projeto de Lei ${ }^{\circ} 11.769$, de 18 de agosto de 
2008. Ela é responsável pela alteração do parágrafo da LDB, agora posicionando a música como conteúdo obrigatório no componente curricular e especificando a formação necessária por parte do docente (MEC, 2008). Nela consta no parágrafo $6^{\circ}$, que "a música deverá ser conteúdo obrigatório, mas não exclusivo, do componente curricular", e "os sistemas de ensino terão três anos letivos para se adaptarem às exigências estabelecidas" (BRASIL, 2008).

Conforme Lopardo (2014):

O foco deve ser a avaliação do impacto da Lei em termos locais, com adaptações das exigências da legislação às características de cada região, de cada escola e visando atingir uma educação musical de qualidade, com professores qualificados e espaços adequados para o desenvolvimento da área (LOPARDO, 2014, p. 21).

Em 02 de maio de 2016 é ratificada a Lei 13.278 que altera o parágrafo $6^{\circ}$ da Lei $n^{\circ}$ 9.394 de 1996, o qual declara as artes visuais, a dança, a música e agora também o teatro, como linguagens que constituirão o componente curricular, e o prazo para que os sistemas de ensino implantem as mudanças decorrentes desta lei, incluída a necessária e adequada formação dos respectivos professores em número suficiente para atuar na educação básica, é de cinco anos (BRASIL, 2016).

Já a Base Nacional Comum Curricular (BNCC), "documento de caráter normativo que define o conjunto de aprendizagens essenciais que todos os alunos devem desenvolver ao longo das etapas e modalidades da Educação Básica" (BRASIL, 2018, p. 7), propõe que a abordagem das linguagens artísticas articule seis dimensões do conhecimento: criação, crítica, estesia, expressão, fruição e reflexão (BRASIL, 2018, p. 194). Nela, cada uma das quatro linguagens do componente curricular constitui uma unidade temática que reúne objetos de conhecimento e habilidades articuladas (BRASIL, 2018, p. 197). O documento ainda acresce uma quinta unidade temática, Artes Integradas, que deve explorar as relações e articulações entre as diferentes linguagens e suas práticas, inclusive aquelas possibilitadas pelo uso das novas tecnologias de informação e comunicação. Complementando, salienta que os critérios de organização das habilidades citadas, são possibilidades e não devem ser tomados como padrão obrigatório para o currículo escolar (BRASIL, 2018). Isso é importante já que na maioria das vezes é o contexto social em que se está inserido que define os direcionamentos dos planejamentos de aula.

Assim, o percurso do ensino das artes no Brasil dentro da amplitude e complexidade dos conceitos de arte e pela visão dos profissionais dedicados à área, busca pela presença constante de um saber significativo fundamental à formação plena do sujeito. Esse é um dos rumos e desafios já que o sistema das políticas educacionais hoje diversifica sua oferta, mas 
desconsidera a amplitude de suas propostas em dissonância com o caráter formativo dos professores, podendo resultar em atuações polivalentes.

\title{
ENSINO DE MÚSICA NAS ESCOLAS: UM OLHAR PARA OS CONTEXTOS DAS PRÁTICAS
}

\section{“[...] a música é feita para ser bela e para proporcionar experiências de beleza, [...] a beleza existe para dar alegria, a alegria estética, que é uma alegria específica, diferente dos prazeres de que habitualmente desfrutamos, e que constitui um dos aspectos da alegria cultural" (SNYDERS, 1992, p. 11).}

O estudo da música, em diversas dimensões, apresenta elementos de integração social, desenvolvimento criativo e expansão cultural, como escreve Snyders (1992), há beleza na música e ela produz 'alegria cultural'. Embora seja uma das linguagens artísticas mais presentes nos âmbitos sociais e midiáticos, se percebe que existe um distanciamento entre pessoas que tem com ela uma relação mais profunda de estudo, leitura e apreciação, de pessoas que dela usufruem seu aspecto funcional (lazer, diversão, rituais, ambiência etc.). Seu sentido formativo e intencionalidade costumam ser aprofundados por artistas, entusiastas ou pessoas envolvidas mais diretamente com a arte, uma delimitação que resulta em uma indústria cultural $^{4}$ com fins comerciais, muitas vezes posicionando iniciativas artísticas legítimas como triviais e impondo estéticas pelo interesse do mercado à grande população.

Embora a música seja reconhecida como parte fundamental da história da civilização e como ferramenta para o desenvolvimento de inúmeras capacidades cognitivas, se sabe que no contexto educacional brasileiro é ainda reduzido o número de pais e professores, entre outros, que conhecem o valor da música no processo de educação da criança (JOLY, 2003, p. 113). Conforme a autora:

\begin{abstract}
A inserção das artes, incluindo a música, no processo de formação do indivíduo, está sendo muito valorizada por algumas sociedades atualmente. Na grande maioria dos países desenvolvidos, como Estados Unidos, Canadá, Austrália, Alemanha, Holanda, Finlândia, entre outros, há um reconhecimento de que a educação musical, seja ela formal ou informal, ensina às crianças requisitos importantes para a vida adulta (JOLY, 2003, p. 113).
\end{abstract}

A legislação educacional estabelece há décadas um espaço para as artes em suas diversas linguagens nas escolas regulares de educação básica. Contudo, sua presença tem sido marcada por indefinição, ambiguidade e multiplicidade (PENNA, 2012, p. 122). Estando ausente das escolas brasileiras, mais recentemente recuperando seu grau de importância em

\footnotetext{
${ }^{4}$ Indústria cultural compreendida como um sistema que usa das expressões artísticas como produto de consumo na sociedade capitalista, composta por inúmeras organizações que normatizam os processos de acesso a determinados conteúdos, visando principalmente o lucro.
} 
meio a um mundo globalizado que clama por sujeitos criativos e culturais, qualidades desenvolvidas e aprimoradas com o estudo de música, a educação musical passa por transições e uma falta de homogeneidade (LOUREIRO, 2012).

É preciso reconhecer que as linguagens artísticas passaram por etapas e ações que lhe condicionaram um papel secundário no currículo escolar nas últimas décadas. Além disso, a disciplina responsável por este trabalho vem sendo fortemente relacionada com as artes visuais em sua associação de conteúdos, estéticas e técnicas, resultando em uma prática limitada com a experiência artística à apenas uma área. Mesmo que se reconheça que se tem procurado aprimorar essas dinâmicas de trabalho, ampliando o contato com diferentes linguagens, em especial com a música. Como indica Lopardo (2014, p. 60):

[...] a música, como componente ou conteúdo curricular, se adapta a um novo meio, a escola. Mas simultaneamente a escola, como comunidade educativa, se adapta à presença da música. Assim, os processos de inserção da música na escola adquirem uma dimensão maior, gerando movimentos em todas as suas partes. Desta forma, a escola se adapta a uma nova situação trazida pela presença da música, a qual se insere progressivamente modificando o seu próprio contexto.

Tais relações acarretam uma (necessária) reformulação da prática pedagógica, tanto estrutural e curricular quanto, e especialmente, de caráter formativo dos professores atuantes.

São muitos os problemas enfrentados pela área. Dentre eles, a falta de sistematização do ensino de música nas escolas de ensino fundamental e o desconhecimento do valor da educação musical como disciplina integrante do currículo escolar (LOUREIRO, 2012, p. 109). Ainda, a rigidez e imobilidade dos sistemas e dos modelos de ensino que insistem em regular todo o processo educativo, direcionando desde os objetivos até as formas de avaliação (LOUREIRO, 2012, p. 163). De acordo com a autora:

\footnotetext{
Não se pode propor uma maneira única de organizar o currículo, principalmente porque a organização do conhecimento não admite regras universais. [...] diante da multiplicidade e da variedade de informações a que estão expostos crianças e jovens, um dos objetivos para a compreensão da cultura musical é encontrar o fio condutor, [...] para que os alunos estabeleçam correspondência com outros conhecimentos e com sua própria vida (LOUREIRO, 2012, p. 177).
}

Existe uma relação pedagógica que deve ser formada antes da imposição de certos elementos que inicialmente soarão para muitos como incompreensíveis ou mesmo cansativos. "Não é a técnica que ensina, mas sim o seu uso em função do que ela permite realizar" (JOLY, 2003, p. 123).

A escola de Educação Básica apresenta inúmeros desafios para o educador musical, na medida em que oferece condições de trabalho distintas da escola especializada em música (quanto ao tamanho das turmas, recursos, instalações etc.), e seus alunos trazem para a sala de 
aula vivências musicais diferenciadas e variadas expectativas em relação à aula de música. Assim, este contexto escolar se diferencia (ou mesmo se opõe) ao modelo tradicional de ensino de música, de caráter técnico-profissionalizante, que ainda marca a formação da maioria dos professores de música (PENNA, 2012, p. 150).

Por outro lado, a educação musical tem cada vez mais fortalecido seu compromisso com a Educação Básica e aumentando o estudo da prática pedagógica, este, aperfeiçoado com os cursos específicos de graduação em Licenciatura em Música ou Pós-graduação na área. Para isso, vem trabalhando o contexto em que se encontra o aluno, aproximando-se de sua realidade sociocultural para então lhe proporcionar e desenvolver novos conhecimentos e experiências.

São muitas as questões que se deve observar ao buscar compreender o contexto o qual se encontra os discentes. A influência familiar e da comunidade, as tecnologias de acesso e consequentemente os objetos relacionados ao consumo imposto pela mídia, que frequentemente são assimilados sem um filtro crítico, ocasionando um distanciamento ou uma apatia de músicas ausentes do grande círculo midiático. Em razão disso, tem-se o objetivo de proporcionar outros saberes e experiências artísticas, contudo, sem deixar de buscar relações com o contexto social em que se está inserido e sem passar a ideia de negação de diferentes realidades. O papel da escola como espaço de aprendizagem, pode ser - no caso do ensino de música - espaço para a cultura em sentido plural, fomento para a criatividade, a autossuperação, a descoberta, a experimentação, a alegria, como afirma Snyders (1992). A alegria de saber, de conhecer, de escolher com criticidade, de apreciar a diversidade, de humanizar-se pela arte.

\section{PESSOAS MAIS HUMANAS, COM EMPATIA, MAIS SOCIÁVEIS: COM A PALAVRA, OS GESTORES ESCOLARES}

“[...] uma educação crítica, radical, não pode jamais prescindir da percepção lúcida da mudança que inclusive revela a presença interveniente do ser humano no mundo" (FREIRE, 2014, p. 34).

Como o objetivo foi analisar que lugar ocupa o ensino de música na rede particular de educação de acordo com a visão da gestão/coordenação escolar, foi aplicado um questionário e para isso foi utilizado um formulário configurado em quinze questões enviados aos gestores via Google Forms. Como resultado, foram obtidas cinco respostas de instituições particulares que oferecem o ensino desde a Educação Infantil até o Ensino Médio.

A partir da pesquisa efetuada, foram levantados os dados: de cinco escolas pesquisadas, sendo três de Bento Gonçalves e duas de Caxias do Sul, uma oferece Educação 
Infantil, duas oferecem Ensino Médio e duas oferecem Ensino Infantil, Fundamental e Médio.

Para facilitar o entendimento e análise das respostas, adotamos a seguinte designação:

- Educação Infantil: escola 1;

- Ensino Médio: escola 2; escola 3;

- Ensino nos três níveis de educação: escola 4; escola 5.

As perguntas um a três eram de múltipla escolha e possibilitaram mais que uma resposta, por indicarem os diferentes espaços que a música ocupa na organização escolar.

Ao questionar sobre o lugar que a música ocupa no currículo escolar, os gestores das escolas 1, 2, 3 e 5 indicaram que o conteúdo é ministrado na disciplina de artes. Mas os gestores das escolas 3, 4 e 5 ainda acrescentaram que uma oferta separadamente estava disponível, assim como a oportunidade de participar em contraturno, opcionalmente, no caso das escolas 3 e 5 . Posto isso, percebemos a predominância já prevista de encontrar a música diluída na disciplina de Artes, algo muito presente no ensino público - legalmente aceito -, e sua oferta como atividade extracurricular, algo mais comum na rede particular. Sua oferta simultânea nas aulas de Artes e em atividades complementares também foi citada pelas escolas 3 e 5.

No tópico seguinte, ao indagar sobre a formação acadêmica do professor atuante, se verificou que nas escolas 3, 4 e 5 os professores possuem graduação em música ou licenciatura em música. As escolas 1 e 2 apontaram que seus professores não possuem formação na área musical. As escolas que indicaram o professor com formação são as escolas que oferecem o ensino separadamente, embora também indiquem que o ensino ocorre na disciplina de Artes, o que dá a entender que os trabalhos ocorrem em ambos os espaços, podendo ser com diferentes professores. As escolas que trabalham com professor sem formação na área já tinham indicado que o ensino de música ocorre na disciplina Artes. Ninguém marcou as outras duas opções disponíveis, "graduação em outro curso, mas com especialização em música" e "professor de música sem graduação (instrumentista, cantor, regente)".

É significativo ressaltar a importância da formação e do conhecimento para a área de atuação, conforme expõe Joly (2003, p. 123):

O professor deve possuir uma capacidade que o habilite a realizar sua tarefa com êxito e com o máximo de rendimento. Essa capacidade compreende um conhecimento profundo sobre a matéria que se ensina e sua preparação pedagógica para tanto. Seria impossível ser um bom professor sem essas duas capacidades. $\mathrm{O}$ professor deve ser então, um profundo estudioso de si mesmo, da criança e daquilo que deseja ensinar. 
Em relação ao processo de formação do professor da Educação Infantil, "poucos são os que afirmam ter algum saber na música, embora alguns se autorizem a apropriar-se dela, mesmo não possuindo um saber formalizado na área” (BEYER, 2003, p. 102).

Conforme Bellochio (2003, p. 129):

[...] por um lado, temos a música presente no cotidiano de nossas vidas, impulsionando várias formas de nos relacionarmos com o mundo; por outro, ainda não temos um processo suficientemente articulado e refletido, que possamos entender e significar como educação musical formal na formação de professores.

Reconhecemos que estas são reflexões que cabem ao ensino como um todo, não somente à formação dos professores especialistas em música. Para compreender como ocorrem as práticas musicais nas escolas, foi indagado sobre suas atividades, o que possibilita uma leitura um pouco mais específica em relação à sua oferta de acordo com a formação do professor. Das possibilidades oferecidas, as alternativas selecionadas foram: musicalização infantil, escolas 1, 4 e 5; disciplina de música, escola 5; aula de instrumento (individual ou coletiva), escola 3; coral/grupo vocal, escola 3 e 5; grupo instrumental, escola 3.

Ainda foi indicado pela escola 3, de Ensino Médio, a partir da opção do questionário "outras atividades", que "ocorrem apresentações mensais dos alunos que participam das aulas de música no intervalo do almoço dos alunos”. Sua abordagem e oferta do ensino de música parece ser a mais abrangente, visto que a atividade é oferecida dentro da disciplina de Artes e em separado, com diferentes atividades direcionadas ao ensino de música, com professor formado na área, além de ocorrerem apresentações dos alunos sem depender de uma data ou evento comemorativo, o que usualmente ocorre no cotidiano de outras instituições escolares. São estratégias essenciais no estímulo e valorização da prática dos alunos.

A escola 2, de Ensino Médio, apontou que também ocorrem "aulas diversificadas de acordo com organização na aula de artes, violão, vocal”. É indicado aulas diversificadas com violão e canto, mas anteriormente foi indicado que o professor não tem formação na área de música. Isso pode não ser um impeditivo, mas é importante destacar já que não foi informado que o professor de Artes teria alguma outra formação em música.

A escola 1, de Educação Infantil, trabalha a musicalização infantil dentro da aula de Artes, com professor sem formação na área. A escola 4, que conta com os três níveis de educação, trabalha a música apenas na Educação Infantil através de aulas de musicalização, ofertadas separadamente e contando com professor formado na área. Chama a atenção a escola não ofertar outras atividades relacionadas em nenhum dos três níveis de educação, apenas como atividade complementar para a Educação Infantil. A escola 5, com os três níveis 
de educação, tem uma abordagem ampla com atividades inseridas dentro da aula de Artes e ofertadas separadamente, contando com professor formado na área de música. Como são escolas com mantenedoras diferentes e distintas propostas pedagógicas, a diversidade e a multiplicidade de condições quanto ao ensino de música é uma realidade.

As perguntas quatro a doze referiram-se a aspectos estruturais e curriculares, e foram de caráter descritivo. A pergunta quatro indagou se é oferecida alguma estrutura específica para as aulas de música, como instrumentos ou sala específica. A escola 3 indicou que possui salas para aula de música; a escola 4 que dispõe de sala de música com vários instrumentos; a escola 5 que há uma sala de aula, como espaço disponível para as aulas de música e na própria sala da turma, "fica a critério de a educadora escolher onde quer ministrar sua aula". Deramse duas respostas de que não existe um espaço específico. A escola 1 apontou que as atividades são realizadas em sala de aula; a escola 2 que "as atividades nas aulas de artes que envolvem a música são feitas em diferentes espaços da escola. Não há local específico".

Das escolas que possuem local específico, apenas a escola 4 citou haver instrumentos. As demais ou não citaram, ou dão a entender que é responsabilidade do aluno providenciar. Estas são as escolas 3 e 5, que oferecem atividades extracurriculares, envolvendo práticas instrumentais e o canto. As que não possuem sala específica são as que têm o ensino de música ministrado na disciplina de Artes.

As perguntas cinco e seis estavam relacionadas às linguagens artísticas presentes no currículo escolar e quais professores as ministram. A pergunta cinco questionou que outras linguagens artísticas estão presentes no currículo da escola e como ocorre sua oferta. A escola 1 trabalha com teatro ofertado pelo profissional da turma. Pode ser assinalado como o trabalho de pedagogo na Educação Infantil que envolve o lúdico multidisciplinarmente. A escola 2 possui atividades com teatro, dança e artes visuais. A escola apontou não ter local específico nem professor com formação específica em música. Embora esta pesquisa não tenha aprofundado a relação de outras linguagens no currículo escolar e como ocorre sua oferta, se subentende que para ocorrerem aulas de teatro e dança existe um local específico e professores com formação na área. Isso demonstraria uma preocupação e envolvimento com as diferentes linguagens artísticas no componente curricular, dando a entender que dentre elas a música seria tratada com a mesma importância. Lembramos que a dança é dependente de vários elementos da música para seu desenvolvimento. A escola 3 indicou que aulas de teatro, artes visuais e dança são ofertadas dentro da grade curricular do primeiro ano do Ensino Médio e como atividades complementares para os demais anos do Ensino Médio, no turno contrário. A escola apontou a música com diferentes abordagens curriculares e professor com formação na área, além do incentivo a apresentações dos trabalhos realizados pelos alunos. A 
escola 4 dispõe somente da disciplina de musicalização na Educação Infantil. Embora sua oferta contemple os três níveis de formação, a resposta dá a entender que não está presente a disciplina de Artes nos demais anos da escola, o que contraria as diretrizes e legislações que a colocam como componente obrigatório. É possível que tenha ocorrido um erro de interpretação em relação ao que foi questionado. Por fim, a escola 5 oferece aulas de música e artes visuais para a Educação Infantil, e aulas de Artes para as turmas do ensino fundamental. Aqui se supõe que quando é mencionada a aula de Artes, está sendo indicado um trabalho com as diferentes linguagens. Chama atenção ela não estar presente no Ensino Médio.

A pergunta seis indagou se o professor que leciona música também trabalha com conteúdos de outras linguagens artísticas. As escolas 3, 4 e 5 indicaram que não. A escola 3 ainda pontuou que "o profissional de música trabalha com os conteúdos e objetos de estudos desse componente. Assim, fica responsável o professor regente trabalhar os outros conteúdos na disciplina de linguagem artística visual". As escolas 1 e 2 indicaram que sim, pois "são conteúdos que fazem parte da grade".

A pergunta sete levantou o questionamento quanto a exibições, amostras e apresentações das diferentes linguagens artísticas. Questionou se estas ocorrem em datas comemorativas ou em fins de período letivo. A escola 1 indicou que estas apresentações ocorrem ao final do ano. A escola 2 que existe dois projetos relacionados à dança, música e teatro, o qual um deles envolve apresentações no centro cultural de sua cidade. As escolas $3 \mathrm{e}$ 4 indicaram que elas ocorrem. A escola 5 indicou apresentações em datas comemorativas, "dia das mães, pais, festa junina e Natal. Temos também outras apresentações artísticas durante o ano que envolvem teatro, dança e apresentação musical".

As festas são uma prática cotidiana na rotina escolar, reúnem os pais e a comunidade para um momento em que é possível perceber os trabalhos que foram realizados pelos alunos (BEYER, 2003).

Beyer (2003) ainda reflete que:

Entre as "coisas boas" que a escola oferece surge a música, acenando, inclusive, como um possível marketing da escola. Para que isso ocorra, a música tem de estar presente nas festinhas, na forma de um show, muitas vezes em detrimento do próprio trabalho de música realizado na escola. Não raro, a escola nem mesmo conta com o ensino contínuo de música, restringindo-se a apresentação a mostrar uma imagem fictícia, de algo que efetivamente não corresponde à aprendizagem das crianças (BEYER, 2003, p. 106).

Decorridos tantos anos, a afirmação de Beyer continua valendo para diversas escolas. Ressaltamos que o espaço das Artes se configura como uma oportunidade de aprendizado ao 
proporcionar um mínimo de trabalho mais direcionado com música, mas também é importante pontuar os aspectos do discurso decorrente dessas apresentações e não das aulas em si.

A questão oito indagou quais anos escolares são contemplados com o ensino de música. A escola 1 indicou que todos os anos. A escola 2 apontou que não, "somente o primeiro ano [do ensino fundamental] tem artes. As demais turmas são envolvidas nos projetos que abordam a música". Já a 3 indicou que "todos os anos, no primeiro ano é disciplina obrigatória e no segundo e terceiro ano o ensino de música se dá nas atividades complementares". A escola 4 informou que apenas a Educação Infantil e anos iniciais são contemplados. A escola 5 seguiu a mesma linha, expos que "apenas a Educação Infantil, crianças de 3 a 5 anos" possuem em seu currículo, as demais são contempladas em projetos. Ou seja, o nível de Educação Infantil é contemplado nas três escolas que a ofertam. Com a exceção da escola 1 que é apenas de Educação Infantil, nenhuma das demais tem a música presente como componente obrigatório em todos os anos escolares.

A pergunta nove complementou a anterior, se referiu a como ocorre a organização do conteúdo de música por ano escolar. Esta questão visava identificar quais eram os critérios estabelecidos na hora do planejamento das aulas/atividades relacionadas. Contudo as respostas tomaram outros direcionamentos. A escola 1 apontou que "os conteúdos são organizados conforme BNCC". A escola 2 indicou "primeiro ano entra na disciplina de artes". A escola 3 não soube responder. A escola 4 "através das Diretrizes Curriculares". A escola 5 que "os conteúdos são divididos entre os trimestres". São citados documentos normativos, mas nenhum deles é aprofundado. Os direcionamentos de cada um deles são amplos, assim a resposta ganhou um caráter mais generalista.

A pergunta 10 se referiu à quantidade de horas/períodos utilizados para as aulas. As escolas 1 e 4 apontaram aulas uma vez por semana. A escola 2 indicou "aula de artes uma vez por semana, a música não tem dia fixo". A escola 3, que "no primeiro ano um período de 45 minutos por semana, nas atividades complementares são ofertadas $2 \mathrm{~h}$ por semana". Já a escola 5 que "são oferecidos 50 minutos semanais". Quanto à oferta da disciplina no aspecto de carga horária, a BNCC orienta um espaço mínimo de dois períodos semanais (BRASIL, 2018). Souza (2010, p. 5) ressalta que:

Professores de Arte concordam que todas as séries do Ensino Fundamental deveriam ter como requisito mínimo duas horas por semana de aulas de Arte. Na prática, ainda são poucas as escolas públicas que conseguem manter um oferecimento regular e qualificado na área de Artes.

A citação se refere ao ensino público, mas como a pesquisa demonstra, sua relação se dá também no ensino privado. "A dificuldade dos professores em manter a disciplina como 
parte integrante do currículo contrastam com as tarefas cada vez mais abrangentes com que eles se defrontam em decorrência da ampliação do conceito de arte" (SOUZA, 2010, p. 5).

A pergunta onze questionou quais os resultados esperados e que competências os alunos devem desenvolver nas aulas de música, considerando sua interação social, escolar e familiar. A escola 1 descreveu "ritmo, tempo correto das notas, entonação vocal, organização social, ampliação do vocabulário, pronúncia correta das palavras, entre tantas outras". A escola 2 indicou que "nos projetos que envolvem música o resultado é muito bom visto que no envolvimento do aluno e família são excelentes, além de auxiliar na desinibição do aluno". A escola 3 "relacionamento interpessoal, comunicação, raciocínio lógico, atenção, concentração". A escola 4 "desenvolvimento das habilidades musicais, emocionais, atenção e dos valores humanos". E a escola 5 que "esperamos desenvolver a musicalização e as habilidades cognitivas e intrapessoais".

Os apontamentos destacaram conceitos importantes, mas também de discurso comum da relevância do ensino de música. Mostraram que existe o entendimento, pelo menos em teoria, de sua contribuição na vida escolar. No entanto é importante destacar que para a compreensão de determinados conhecimentos e desenvolvimento de habilidades se faz necessário uma abordagem mais profunda e prolongada do conteúdo, o que exige um educador com formação adequada e um espaço curricular que abrange mais períodos e anos escolares para um possível desenvolvimento destas competências, o que requer uma infraestrutura apropriada.

A questão doze questionou se ocorre alguma dificuldade/obstáculo para a manutenção da aula de música. As cinco escolas apontaram que não ocorrem dificuldades. A escola 3 ainda pontuou que "o trabalho com diferentes linguagens sempre foi um diferencial da escola e é algo muito valorizado pela equipe de gestão, professores, alunos e famílias". As dificuldades questionadas poderiam sugerir aspectos de infraestrutura ou participação dos alunos, contudo nada foi mencionado.

As perguntas treze a quinze indagaram os entrevistados quanto suas opiniões em relação ao ensino de música na escola e suas contribuições para o aluno e a sociedade. Estes são apontamentos demasiado importantes, pois relacionam as visões pessoais dos gestores quanto ao ensino de música. A questão treze questionou diretamente a opinião do gestor sobre o ensino de música na sua instituição. $\mathrm{O}$ gestor da escola 1 escreveu que "trabalhamos com música na organização da rotina escolar há mais de 15 anos e entendemos que ela facilita o direcionamento de qualquer atividade". Conforme o gestor da escola 2, "como é numa instituição de Ensino Médio, não se têm a obrigatoriedade, porém quando é proporcionado ao aluno e os resultados são muito bons. Sou de acordo em termos a música como disciplina para 
auxiliar o aluno no seu desenvolvimento e no Ensino Médio a música auxilia muito o aluno a lidar com a ansiedade, a timidez, a dicção". Na escola 3 que "o ensino de música possibilita inicialmente aos alunos se conhecerem e identificarem potenciais até então não descobertos por eles. A partir da identificação pessoal com essa forma de linguagem, é possibilitado ao aluno a continuidade do aprendizado nas atividades complementares. A música une os alunos com objetivos comuns, possibilita ocuparem o tempo de forma saudável, contribui para o desenvolvimento de outras competências e auxilia na comunicação e no relacionamento interpessoal". A escola 4 apontou apenas que "não ficaria mais sem essa oferta". Já a escola 5 destacou "acredito ser indispensável. A música desperta o lúdico, os sentimentos e os sentidos".

É importante apontar os aspectos de 'mercado' o qual as escolas estão inseridas. Como estamos falando da gestão escolar, parte dela a administração dos custos e direcionamento de investimentos. Em uma realidade em que o que rege suas diretrizes são o desempenho dos estudantes em vestibulares e provas semelhantes, e que as artes não ocupam espaço "privilegiado" nestas avaliações, resulta que não se dá a devida importância. No entanto, no aspecto de formação que cabe à escola, se os apontamentos são tão positivos e se a educação musical resulta em tantos retornos à instituição, famílias e alunos, por que não se investe mais nela? Lopardo (2014, p. 108), quanto à reorganização da instituição, aponta que:

É necessário avaliar o impacto dessa reorganização curricular, tanto na comunidade escolar quanto no sistema que recebe um novo elemento para interagir e se adaptar à dinâmica escolar, na situação econômica ao incluir mais horas na matriz curricular ampliando os custos, incrementando também na compra de materiais para o desenvolvimento da disciplina e reestruturação do espaço físico para poder receber as diferentes turmas.

Essa forma positiva dos gestores em olhar a educação musical foi recorrente nas próximas respostas. A pergunta quatorze indagou quais as possíveis contribuições que o ensino de música pode oferecer na formação dos estudantes. Para o gestor da escola 1, "a música auxilia muito na construção de um bom vocabulário, na construção de rimas e na interpretação de textos. Ela facilita a interação com o grupo despertando a atenção, estimulando a concentração e o foco durante o aprendizado. Além disso, facilita a memorização dos conteúdos". O gestor da escola 2 apontou "pessoas mais humanas, com empatia, mais sociáveis". O gestor da escola 3, a "melhora do relacionamento interpessoal, auxilia no aumento da autoestima na adolescência, ajuda no desenvolvimento da atenção, concentração e foco, melhoria na comunicação, na apresentação individual e fortalece o trabalho em equipe". Já o da escola 4, a "apreciação pela Arte". Da escola 5, "a música pode possibilitar à criança diferentes vivências e no que se refere à sua formação, pode desenvolver 
o respeito, o brincar, o imaginar, aprender e o observar, e assim construir sua identidade". Aqui se reitera novamente que certos conhecimentos e habilidades não são desenvolvidos e aprimorados prematuramente ou com contato superficial, parecendo que certos apontamentos são mais teóricos do que factuais. Alguns demandam maturidade e experiência de vida escolar para fazerem sentido dentro do contexto de construção de identidade da criança/jovem, além de não se fazerem facilmente quantificáveis a ponto de serem determinados como resultantes. É certo que esses se referem às possíveis contribuições aos estudantes, mas se espera que estejam próximos da realidade de suas instituições.

Por fim, a partir da visão do gestor, se questionou como o ensino de música pode contribuir (ou não) para a sociedade como um todo. $O$ gestor da escola 1 escreveu que "infelizmente o caminho da música na nossa educação ainda é bem lento e pouco estimulado. Mesmo agora dentro das novas configurações da nova legislação muito tem a se reconhecer. A música orienta e organiza a rotina da Educação Infantil; trabalha o respeito, a atenção, cobra pela disciplina e auxilia muito o 'brincar' direcionado". O gestor da escola 2 assinalou que a "contribuição será positiva em todos os sentidos. Desenvolve o cognitivo, teremos pessoas mais autônomas, com uma melhor autoestima, uma sociedade disciplinada, culta, criativa e crítica". A gestão da escola 3 ressaltou que "o ensino de música forma cidadãos mais atentos e sensíveis ao que ocorre ao seu redor". A gestão da escola 4 expôs que "contribui muito! A beleza e o respeito pela arte iniciam desde cedo". Finalmente, da escola 5, obtivemos que "a música produz cultura, desse modo, seu ensino forma cidadãos com múltiplas linguagens e reflexivos que podem contribuir para as diferentes manifestações culturais e sociais".

É importante pontuar que a legislação melhorou quando reconhece e obriga o ensino de música nas escolas, bem como define os critérios de formação por parte do professor. $\mathrm{O}$ que precisa melhorar é a sua implantação, e é a gestão em primeira instância que articulará os componentes curriculares, os docentes e alunos à sua realização. Através de "uma gestão inovadora, a valorização do aluno, do professor e da escola, o diálogo e o trabalho coletivo, a participação da família e da comunidade, a ressignificação do espaço físico, o incremento da sociabilidade e a construção do sentido de pertencimento". (LOPARDO, 2014, p. 62). Não são somente aspectos diretamente associados à música que fazem essa prática dar certo, mas a construção do coletivo.

\section{PARA CONCLUIR... UM NÃO-LUGAR}

"à arte da criança possui qualidades e valores: a criança descobre que é capaz de se expressar, e que aquilo que ela expressa participa de sua autoconstrução e da exploração de mundo" (SNYDERS, 1996, p. 65) 
Ao findar, podemos citar como pontos importantes a música estar de alguma forma presente nas cinco instituições, em três delas com professor formado na área e ainda serem ofertadas atividades extracurriculares aos alunos que querem aprofundar seus estudos/práticas. Porém, observa-se a construção de uma narrativa polida, um discurso de certa forma "bonito" no que confere aos aspectos da relevância da educação musical para todos os componentes da sociedade. Mas às respostas faltou manifestar uma realidade tangível de suas instituições, o que efetivamente se deseja fazer para tornar o ensino de música uma prática formativa que contribua para a educação naqueles contextos educacionais. A música se constitui em um não-lugar como prática cotidiana, seu aparecimento é fortuito e ligado a atividades extracurriculares ou aos períodos de comemorações festivas.

Em primeira análise, existe um silêncio, a ausência de informações mais objetivas. Com exceção da gestão da escola 3 e 5 que apresentaram de forma mais detalhada a constituição do ensino em suas escolas, a música não possui um lugar no currículo especificado, com horário, sala e organização de uma prática de ensino regular. Em todas faltam apontamentos de seus planejamentos, divisões de conteúdo, objetivos e avaliações. Os gestores e coordenadores muitas vezes não sabem responder porque não existe esse lugar. Há uma diluição dos fazeres ou então eles são pontuais /eventuais.

Existe o discurso da importância e do retorno, mas não existe uma regularidade que justifique e efetivamente dê conta do ensino de música no cotidiano dessas escolas. $\mathrm{O}$ desenvolvimento de um pensamento crítico depende de inúmeros fatores, em qualquer nível da Educação Básica e mesmo após ela os jovens dependem de uma constância e uma profundidade, como se objetiva em outras disciplinas. Tópicos musicais mais técnicos, a música como valor humano e emocional, são temas complexos que exigem estudo contínuo e direcionado, o que não ocorre. Nem mesmo a dimensão cultural, da alegria produzida pela música como linguagem e como arte é mencionada. Tampouco aspectos de legislação foram propriamente apontados.

A música aparece como algo lateral, eventual e efêmero, talvez trabalhado em outras disciplinas. Atividades mais específicas são extrassala, extracurriculares, pois o que é citado como trabalho na escola, por vezes foge do nível de ensino ou espaço curricular ofertado pela instituição. Há uma inconstância, desregularidade, respostas genéricas e teoricamente adequadas.

Consideramos que a escola trabalha a música mais frequentemente num caráter de exposição de trabalhos, que consideram e aproximam alunos com pré-disposição às atividades com um professor responsável, mas sem ter esses conhecimentos ministrados em aulas 
regulares. Os gestores escolares como membros articuladores dos processos educacionais, dentro do contexto em que as escolas estão inseridas, fazem parte de um mercado educacional que prima por avaliações e resultados que objetivam provas de vestibulares, Enem, mercado de atuação, etc., o qual as artes não ocupam lugar de destaque nesse tipo de avaliação e contexto.

Se a música é a arte mais presente em nossas vidas, visto que fazemos inúmeras atividades acompanhadas dela ao mesmo tempo em que ela é usada em todas as mídias (propaganda, cinema, etc.), se ela produz alegria e nos liga à cultura, é de se idealizar que ela possa ser mais aprofundada e ponderada nas instâncias educacionais e consequentemente sociais. Desejamos que ela seja parte do cotidiano das escolas e dos processos formativos, mas esse ainda é um desafio a ser superado.

\section{Referências}

ALVARENGA, C.; MAZZOTTI, T. Análise retórica do debate acerca da obrigatoriedade do ensino de música no Brasil. Revista Educação e Cultura Contemporânea, vol. 9, nº 19, p. $177-205,2012$.

BELLOCHIO, C, R. Educação Musical e professores dos anos iniciais de escolarização: formação inicial e práticas educativas. In: HENTSCHKE, L.; BEN, L. del. Ensino de Música: propostas para pensar e agir em sala de aula. São Paulo: Moderna, 2003. p. 127-140.

BEYER, E. Reflexões sobre as práticas musicais na educação infantil. In: HENTSCHKE, L; BEN, L. del. Ensino de Música: propostas para pensar e agir em sala de aula. São Paulo: Moderna, 2003. p. 101-112.

BRASIL. M, E. Base Nacional Comum Curricular: Educação é a Base. 3. ed. 2018. 600 p. Disponível em: 〈https://goo.gl/8cuVrN>. Acesso em: 15 jan. 2019.

BRASIL. M, E. Assessoria de Comunicação Social. Ensino de música será obrigatório. 2008. Disponível em: <https://goo.gl/vxaY03>. Acesso em: 13 janeiro 2019.

BRASIL. P, R. Casa Civil. Lei $\mathbf{N}^{\circ}$ 9.394, de 20 de dezembro de 1996: Estabelece as diretrizes e bases da educação nacional. 1996. Disponível em: 〈https://goo.gl/nuCQjG〉. Acesso em: 13 janeiro 2019.

BRASIL. P, R. Casa Civil. Lei $\mathbf{N}^{\mathbf{0}}$ 11.769, de 18 de agosto de 2008: Altera a Lei no 9.394, de 20 de dezembro de 1996, Lei de Diretrizes e Bases da Educação, para dispor sobre a obrigatoriedade do ensino da música na educação básica. 2008. Disponível em: <https://goo.gl/PsF4OU>. Acesso em: 13 janeiro 2019.

BRASIL. P, R. Casa Civil. Lei $\mathbf{N}^{\circ}$ 13.278, de 2 de maio de 2016: Altera o $§$ 6o do art. 26 da Lei no 9.394, de 20 de dezembro de 1996, que fixa as diretrizes e bases da educação nacional, referente ao ensino da arte. 2016. Disponível em: 〈https://goo.gl/Z2hdO9>. Acesso em: 12 janeiro 2019.

BRASIL. P, R. Casa Civil. Mensagem No 622, de 18 de agosto de 2008. 2008. Disponível em: <https://goo.gl/kcplh4>. Acesso em: 12 janeiro 2019. 
JOLY, I, Z, L. Educação e educação musical: conhecimentos para compreender a criança e suas relações com a música. In: HENTSCHKE, L.; BEN, L. del. Ensino de Música: propostas para pensar e agir em sala de aula. São Paulo: Moderna, 2003. p. 113-126.

LOPARDO, C, E. A Inserção da Música na Escola: um estudo de caso em uma escola privada de Porto Alegre. 2014. 289 f. Tese (Doutorado) - Curso de Música, Universidade Federal do Rio Grande do Sul, Porto Alegre, 2014.

LOUREIRO, A, M, A. O ensino de música na escola fundamental. 8. ed. São Paulo: Papirus, 2012. $235 \mathrm{p}$.

PENNA, M. Música(s) e seu ensino. 2. ed. Porto Alegre: Sulina, 2012.

QUEIROZ, L. R. S.; MARINHO, V. M. Práticas para o ensino da música nas escolas de educação básica. In: Música na educação básica. Porto Alegre, v. 1, n. 1, out. de 2009.

SNYDERS, G. A escola pode ensinar as alegrias da música? São Paulo: Cortez, 1992.

SNYDERS, G. Alunos felizes. Reflexão sobre a alegria na escola a partir de textos literários. São Paulo: Paz e Terra, 1996.

SOUZA, J. Arte no Ensino Fundamental. Belo Horizonte, 2010. Disponível em: <http://bit.ly/2s7pHC2>. Acesso em: 10 janeiro 2019.

TINHORÃO, J, R. História Social da Música Popular Brasileira. São Paulo: Editora 34, 1998. $381 \mathrm{p}$.

Artigo Recebido: 27 de março de 2021.

Artigo Aceito: 30 de abril de 2021. 